\title{
Viral susceptibility across host species is largely independent of dietary protein to carbohydrate ratios 00
}

\author{
Katherine E. Roberts (D) | Ben Longdon (i)
}

Centre for Ecology \& Conservation, College of Life and Environmental Sciences, University of Exeter, Penryn, UK

\section{Correspondence}

Katherine E. Roberts, Centre for Ecology

$\&$ Conservation, College of Life and

Environmental Sciences, University of

Exeter, Penryn Campus, Penryn, Cornwall,

TR10 9FE, UK.

Email: k.roberts@exeter.ac.uk

\section{Funding information}

Sir Henry Dale Fellowship, Grant/Award Number: 109356/Z15/Z; Royal Society

\begin{abstract}
The likelihood of a successful host shift of a parasite to a novel host species can be influenced by environmental factors that can act on both the host and parasite. Changes in nutritional resource availability have been shown to alter pathogen susceptibility and the outcome of infection in a range of systems. Here, we examined how dietary protein to carbohydrate altered susceptibility in a large cross-infection experiment. We infected 27 species of Drosophilidae with an RNA virus on three food types of differing protein to carbohydrate ratios. We then measured how viral load and mortality across species was affected by changes in diet. We found that changes in the protein:carbohydrate in the diet did not alter the outcomes of infection, with strong positive inter-species correlations in both viral load and mortality across diets, suggesting no species-by-diet interaction. Mortality and viral load were strongly positively correlated, and this association was consistent across diets. This suggests changes in diet may give consistent outcomes across host species, and may not be universally important in determining host susceptibility to pathogens.
\end{abstract}

\section{KEYWORDS}

host-parasite interaction, host shift, invertebrate, phylogenetics, viruses

\section{1 | INTRODUCTION}

A key driver of pathogen host shifts-where a pathogen jumps from one host species to another-is environmental change (Carlson et al., 2020; Hoberg \& Brooks, 2015). For a host shift to successfully occur a novel host must first be exposed to a parasite, which must then be able to replicate and successfully infect the host, before sufficient onward transmission (Woolhouse et al., 2005). Ecological factors can therefore influence the likelihood of host shifts by altering species distributions and abundances-making encounters more likely, or by acting as stressors that alter physiological factors, including immunity or virulence. The ecological factor most studied to date has been temperature, which can have asymmetrical impacts on hosts and parasites and potentially alter the likelihood of host shifts (Brooks \& Hoberg, 2007; Hoberg \& Brooks, 2015; Kirk et al., 2018; Roberts et al., 2018). The role of other ecological traits such as resource availability, humidity, population density and geographical range, or within host ecological traits such as metabolic rate, has been less well studied in the context of understanding the outcomes of host shifts, despite an increasing knowledge of the role such factors play in effecting the outcomes of host-parasite interactions (Blanford \& Thomas, 1999; Cumnock et al., 2018; Harvell et al., 2002; Hayman et al., 2016; Ponton et al., 2013).

Nutrition can shape the outcome of host-parasite interactions through its ability to moderate both parasite virulence and host resistance (Pike et al., 2019; Ponton et al., 2011, 2013). The nutritional resources of a host can impact its ability to resist infection as immune responses are thought to be costly to both maintain and activate (Cotter et al., 2011; Knutie et al., 2017; Kraaijeveld \& Godfray, 1997; Kutzer \& Armitage, 2016; Lochmiller \& Deerenberg, 2000; McKean

This is an open access article under the terms of the Creative Commons Attribution License, which permits use, distribution and reproduction in any medium, provided the original work is properly cited.

(c) 2021 The Authors. Journal of Evolutionary Biology published by John Wiley \& Sons Ltd on behalf of European Society for Evolutionary Biology. 
et al., 2008). Nutrition is known to have long-term consequences, with developmental nutritional status being shown to have latent or even trans-generational effects on immune responses (in Drosophila: Fellous \& Lazzaro, 2010; Savola, Vale, et al., 2020 and reviewed in Grueber et al., 2018). Hosts can also show behavioural modifications in feeding upon infection; for example, parasite-induced anorexia is thought to be an adaptive host response to parasite challenge (Ayres \& Schneider, 2009; Rao et al., 2017). In some cases, hosts actively increase the consumption of certain nutrients in their diet, for example, the African armyworm-S. exempta upon infection with a baculovirus displays macronutrient self-medication (Povey et al., 2009). Nutrition may constrain the amount of investment that a host can allocate to an energetically demanding immune response (Cotter et al., 2011; Knutie et al., 2017; Kraaijeveld \& Godfray, 1997; Lochmiller \& Deerenberg, 2000), and coping with costs associated with a parasite burden if infection does become established (Sheldon \& Verhulst, 1996). A suboptimal nutritional status may lead a host to be unable to suppress or tolerate a parasite challenge they may otherwise have been able to resist; or suffer reduced fitness from a trade-off in resources with life history traits (Cotter et al., 2011; Knutie et al., 2017; Kraaijeveld \& Godfray, 1997; Lochmiller \& Deerenberg, 2000).

From a parasite perspective, infecting a host of suboptimal nutritional status may mean they encounter a weaker immune response, and therefore, infection and establishment is easier (Siva-Jothy \& Thompson, 2002). However, once established the parasite may encounter its own resource limitations due to competition with an already depleted host, causing suboptimal growth and potentially affecting onward transmission. Therefore, predicting the outcome of the interaction between nutrition, host immunity and subsequent resistance is complex as the effects on the two parties may be divergent (Bedhomme et al., 2004).

Multiple life history traits are moderated by resource availability, with condition dependency across reproductive traits, ageing and lifespan (Camus et al., 2017; Henry \& Colinet, 2018; Henry et al., 2020; Lee et al., 2008; Maklakov et al., 2009). Laboratory experiments on dietary restriction, where individuals experienced a reduction in nutrition without inducing malnutrition (differentiated from Calorie Restriction), have been found to extend life span in a range of organisms (Anderson et al., 2003; Klass, 1983; Nakagawa et al., 2012; Weindruch \& Walford, 1982). The effects of dietary restriction appear to be explained by resource-mediated tradeoffs between longevity and reproductive effort (but see review by (Moatt et al., 2020)). Geometric frameworks-the use of artificial diets with known compositions of specific nutrients that develop an understanding of dimensional nutrient space-have been used to examine the consequences of different ratios of macronutrients across a range of organisms (Raubenheimer \& Simpson, 1999; Simpson \& Raubenheimer, 1995, 2011). In Drosophila, different life history traits were shown to be optimized at different proteincarbohydrate intakes (Fanson et al., 2009; Jensen et al., 2015; Lee et al., 2008; Skorupa et al., 2008). Across multiple species, low protein to carbohydrate ratios reduce reproductive rates but maximize lifespan (Le Couteur et al., 2016; Nakagawa et al., 2012). However, individuals with diets higher in protein and lower in carbohydrates have greater reproductive rates but shorter life spans. When given a choice of diet, individuals have been shown to optimize reproduction over lifespan (Bunning et al., 2016). Host dietary frameworks have been used to examine effects on challenge with bacterial pathogens (Cotter et al., 2019; Povey et al., 2009; Savola, Vale, et al., 2020; Wilson et al., 2020), viral pathogens (Lee et al., 2006; Povey et al., 2014) and on individual aspects of the immune system and immune related gene expression (Cotter et al., 2011, 2019; Keaton Wilson et al., 2019). In particular, studies of viral infection in insects have found that high dietary protein leads to increased resistance (Lee et al., 2006), indicating there may be higher protein costs of resistance.

To investigate the effect that host diet has on the susceptibility of different host species, we infected 27 species of Drosophilidae, with Drosophila C Virus (DCV) fed on three diets with varying ratios of protein to carbohydrates but comparable calorie content. We then measured the change in viral load and host mortality across these different diets. DCV is a positive sense RNA virus in the family Dicistroviridae. DCV was isolated from D. melanogaster although has also been detected in the closely related $D$. simulans (Christian, 1987), and in the wild, it is thought to be transmitted faecal-orally (Jousset et al., 1972). Infection of DCV by inoculation is highly pathogenic in adult flies causing increased mortality rates, metabolic and behavioural changes, nutritional stress in the midgut and thought to cause similar pathologies to those seen in starvation (Arnold et al., 2013; Christian, 1987; Chtarbanova et al., 2014; Vale \& Jardine, 2017). DCV shows specific tissue tropism in D. melanogaster, with infection of the heart tissue, fat body, visceral muscle cells around the gut (midgut) and food storage organ (crop) leading to reduced defecation, food blockage and dehydration/starvation (Ferreira et al., 2014). Infection progresses in a similar manner following both oral or septic inoculation, with the same tissues ultimately becoming infected (Arnold et al., 2013; Cherry \& Perrimon, 2004; Chtarbanova et al., 2014; Ferreira et al., 2014). If hosts are in a nutritional environment that allows for investment in immune function or damage repair, they may be more able to resist, or tolerate a novel infection (Pike et al., 2019; Ponton et al., 2011, 2013). This could then lead to different outcomes following a host shift, either the host could manage to suppress the parasite or avoid infection entirely, or could become infected and minimize parasite damage (Howick \& Lazzaro, 2014; Lazzaro \& Little, 2009). Alternatively hosts may be fully susceptible to infection, and enriched resources may act to enhance pathogen virulence by enabling within host-pathogen growth (Hall et al., 2009; Pike et al., 2019). Previous work has demonstrated that following inoculation into a novel host species, the host phylogeny is an important determinant of susceptibility to DCV (Longdon et al., 2011, 2015). The host phylogeny explains a large proportion of the variation in DCV virulence (mortality) and viral load (75\% and $67 \%$, respectively) with high virulence being associated with high viral loads (Longdon et al., 2015). One of the fundamental steps needed for a successful host shift is the ability of a pathogen to infect 
its novel host. Here, we ask if the nutritional environment alters the susceptibility to DCV following a shift into a range of novel host species, and whether such patterns are consistent across species.

\section{2 | METHODS}

\section{1 | Diet preparation}

Three different cornmeal diets were used (Supplementary of species used and food type). The standard cornmeal diet used in our laboratory is comprised of a 1:10 protein to carbohydrate ratio and became our 'Medium'-protein: carbohydrate ratio diet treatment. We also developed two further diets that were approximately isocaloric, a low protein: carbohydrate food (1:20 protein to carbohydrate) and a high protein: carbohydrate food (1:5 protein carbohydrate); see supplementary for full table of food recipes and nutritional breakdown (Supplementary Table S1). These were based around previous findings that suggested that in $D$. melanogaster lifespan was maximized on a protein: carbohydrate ratio of around 1:16, and fitness-measured as lifetime egg production at a ratio of 1:4 (Lee et al., 2008). All diets were manipulated by altering the dextrose and yeast amounts whilst maintaining as close as possible the same calorie content at 142 Calories $\mathrm{g} / 100 \mathrm{ml}$. Yeast was manipulated as it provides the majority of the protein as well as other noncaloric nutritional requirements (Piper, 2017). Values were confirmed using the Drosophila Dietary Composition Calculator (Lesperance \& Broderick, 2020).

\section{2 | Viral infections}

Twenty-seven different species of Drosophilidae were maintained in multigeneration populations, in Drosophila stock bottles (Fisherbrand) on $50 \mathrm{ml}$ of their respective food medium at $22^{\circ} \mathrm{C}$ and $70 \%$ relative humidity with a 12 -hr light-dark cycle (See Supplementary for species and food). Each day, two vials of 0 - to 1-day-old male flies were randomly assigned to one of three potential food types; low, medium or high, protein: carbohydrate ratio. The mating status of flies was not controlled as some species may reach sexual maturity before collection. We only used male flies for this study to remove any potential effect of sex. Flies were kept on their respective food treatments for 5 days, and tipped onto fresh vials of food every day (Blum et al., 2013; Broderick \& Lemaitre, 2012). After 5 days of acclimatization on their food treatment, flies were experimentally infected with DCV. These collections and inoculations were carried out over three replicate blocks, with each block being completed over consecutive days (Figure 1). The order that the species were infected was randomized each day, as was food treatment for each species.

We used Drosophila C virus (DCV) strain B6A (Longdon et al., 2018), which is derived from an isolate collected from $D$. melanogaster in Charolles, France (Jousset et al., 1972). The virus was prepared as described previously (Longdon et al., 2013). Briefly,

\section{Drosophilidae species}

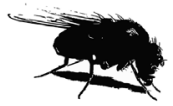

\section{P:C Ratio}

High 1:5 or Medium 1:10 or Low 1:20

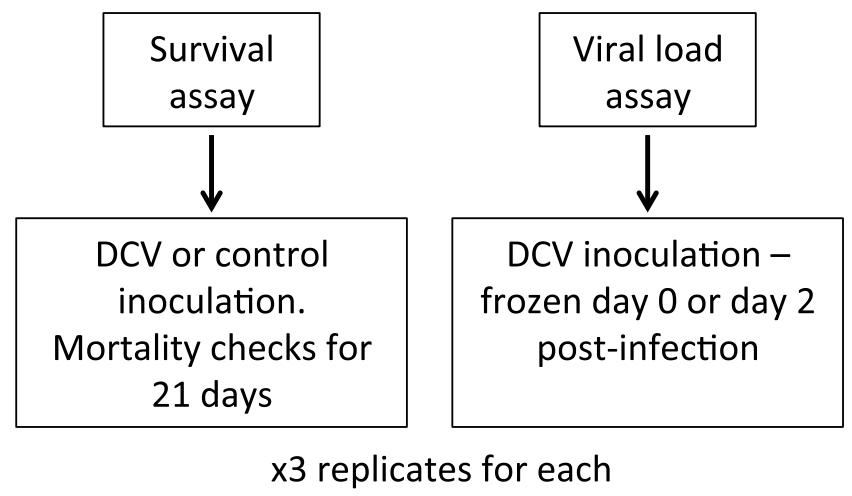

FIGURE 1 Schematic of the experimental set up: males from 27 species of Drosophilidae were housed on three foods with different protein: carbohydrate ratios before being inoculated with DCV or a control sham infection, for a survival assay. Flies were also inoculated with DCV and sampled immediately (day 0 time point) or 2 days post-infection, to measure the change in RNA viral load. For each treatment (control/virus or day 0/day 2), there were three replicates, where each replicate was a vial of flies (number of flies per vial described in methods)

DCV was grown in Schneider's Drosophila line 2 cells and the Tissue Culture Infective Dose 50 (TCID50) per $\mathrm{ml}$ was calculated using the Reed-Muench end-point method. Flies were anesthetized on $\mathrm{CO}_{2}$ and inoculated using a 0.0125-mm-diameter stainless steel needle that was bent to a right angle $\sim 0.25 \mathrm{~mm}$ from the end (Fine Science Tools). The bent tip of the needle was dipped into the DCV solution $\left(\operatorname{TCID} 50=6.32 \times 10^{9}\right)$ and pricked into the pleural suture on the thorax of the flies (Longdon et al., 2015). We selected this route of infection as oral inoculation has been shown to lead to stochastic infection outcomes in D. melanogaster, with injection producing a more reproducible infection, that has been found to follow a similar course to an oral infection, with the same tissues ultimately becoming infected by both methods (Cherry \& Perrimon, 2004; Chtarbanova et al., 2014; Ferreira et al., 2014; Merkling \& van Rij, 2015). One vial of inoculated flies was immediately snap frozen in liquid nitrogen to provide a time point zero sample (day 0 time point) to be used as a reference sample to control for relative viral dose. The second vial of flies was infected and then placed back into a new vial of their respective food treatment. After 2 days ( $\pm 1 \mathrm{hr}$ ), flies were snap-frozen in liquid nitrogen. This time point was chosen based on previous studies that show a clear increase in viral growth but little mortality at 2 days post-infection (Longdon et al., 2015; Roberts et al., 2018). Each experimental block contained a day 0 and day 2 replicate for each species, at each diet (27 species $\times 3$ diet treatments $\times 3$ experimental blocks). In total, we quantified viral load in 7,580 flies in 474 
biological replicates (biological replicate $=$ change in viral load from day 0 to day 2 post-infection), with a mean of 16 flies per replicate (range across species $=8-28$ ).

\section{3 | Survival}

In order to measure the effect of diet on virulence, we also carried out a survival assay where mortality was recorded following infection. The same infection protocol was carried out as above; one vial of flies was infected with DCV, whilst the other was injected using a clean virus free needle dipped in Drosophila Ringer's solution (sham infection) (Sullivan et al., 2000) (Figure 1). Flies were maintained in vials as described above and tipped onto their respective fresh food every 2 days. The number of dead flies was counted every day for 21 days. The survival assay was carried out across three blocks with infections carried out over consecutive days, to obtain a control and infected vial per species each day. Treatment (virus or control) and the order in which fly species were inoculated were randomized between blocks. Diet was randomized across days, so for a given food type a control and viral infected vial was completed each day, and this was repeated over consequent days until there was a control and infected for each species on each food type ( 27 species $\times 2$ treatments (control or challenged) $\times 3$ diet treatments $\times 3$ experimental blocks). In total, we measured mortality in 9,222 flies with a mean of 20 flies per replicate (range across species: 6-30 flies).

\subsection{Measuring the change in viral load}

The change in RNA viral load from day 0 to day 2 post-infection was measured using quantitative Reverse Transcription PCR (qRT-PCR). Frozen flies were homogenized in Trizol reagent (Invitrogen) using a bead homogenizer for $30 \mathrm{~s}$ (Bead Ruptor 24; Omni international) and stored at $-80^{\circ} \mathrm{C}$ for later extraction. Total RNA was extracted from the Trizol homogenized flies in a chloroform isopropanol extraction, reverse-transcribed with Promega GoScript reverse transcriptase and random hexamer primers. Viral RNA load was expressed relative to the endogenous control housekeeping gene

TABLE 1 Inter-specific correlations between viral load and mortality measures across the different diet treatments

\begin{tabular}{lll} 
& Inter-specific correlation & $95 \% \mathrm{Cls}$ \\
\hline $\begin{array}{l}\text { Viral load } \\
\text { Low-Medium }\end{array}$ & 0.93 & $0.85,0.98$ \\
Medium-High & 0.83 & $0.66,0.96$ \\
Low-High & 0.80 & $0.63,0.96$ \\
\hline Survival in virus challenged & \\
Low-Medium & 0.93 & $0.81,0.99$ \\
Medium-High & 0.88 & $0.71,0.99$ \\
Low-High & 0.90 & $0.73,0.99$ \\
\hline
\end{tabular}

RpL32. Primers were designed to match the homologous sequence in each species and crossed an intron-exon boundary so will only amplify mRNA. The primers in $D$. melanogaster were RpL32 qRT-PCR $F$ (5'-TGCTAAGCTGTCGCACAAATGG -3') and RpL32 qRT-PCR R (5'TGCGCTTGTTCGATCCGTAAC -3') (see supplementary table and Longdon et al., 2011). DCV primers were 599F (5'-GACACTGCCTTT GATTAG-3') and 733R (5'CCCTCTGGGAACTAAATG-3') as previously described (Longdon et al., 2015). Two qRT-PCR reactions (technical replicates) were carried out per sample with both the viral and endogenous control primers, with replicates distributed across plates in a randomized block design. QRT-PCR was performed on an Applied Biosystems StepOnePlus system using Sensifast Hi-Rox Sybr kit (Bioline) with the following PCR cycle: $95^{\circ} \mathrm{C}$ for 2 min followed by 40 cycles of: $95^{\circ} \mathrm{C}$ for $5 \mathrm{~s}$ followed by $60^{\circ} \mathrm{C}$ for $30 \mathrm{~s}$. Each qRT-PCR plate contained four standard samples. A linear model was used to correct the cycle threshold $\left(C_{t}\right)$ values for differences between qRT-PCR plates. Samples where the technical replicates had $\mathrm{Ct}$ values more than two cycles apart after plate correction were repeated. To estimate the change in viral load, we first calculated $\Delta C_{t}$ as the difference between the cycle thresholds of the DCV qRTPCR and the RpL32 endogenous control. For each species the viral load of day 2 flies relative to day 0 flies was calculated as $2^{-\Delta \Delta C_{t}}$ ; where $\Delta \Delta C_{t}=\Delta C_{t}$ day $0-\Delta C_{t}$ day2. The $\Delta C_{t}$ day 0 and $\Delta C_{t}$ day 2 post-infection is a pair of $\Delta C_{t}$ values from a day 0 biological replicate and a day 2 replicate.

\subsection{Effect of body size}

To account for any potential differences in body size between species, we measured wing length as a proxy for body size (Huey et al., 2006). During the collections for the viral load assay, males of each species were collected and immediately stored in ethanol. Subsequently, wings were removed and photographed under a dissecting microscope. Using ImageJ software (version 1.48), the length of the IV longitudinal vein from the tip of the proximal segment to where the distal segment joins vein $\mathrm{V}$ was recorded, and the mean taken for each species, overall there was a mean of 28 wings measured per species (range 20-35).

\section{6 | Host phylogeny}

The host phylogeny was inferred as described previously (Longdon et al., 2015) using seven fly genes (mitochondrial; COI, COII, ribosomal; $28 S$ and nuclear; Adh, SOD, Amyrel, RpL32). Publicly available sequences were downloaded from GenBank or were Sanger sequenced. In total, we had RpL32 sequences for all 27 species, $28 \mathrm{~S}$ from 24 species, Adh from 24 species, Amyrel from 15 species, COI from 27 species, COIl from 27 species and SOD from 12 species. For each gene, the sequences were aligned in Geneious (version 9.1.8) (Kearse et al., 2012) using the global alignment setting, with free end gaps and a cost matrix of $70 \%$ similarity. The phylogeny was inferred 
using BEAST (v1.10.4) (Drummond et al., 2012), with genes partitioned into three groups: mitochondria, ribosomal and nuclear, with their own molecular clock models. A random starting tree was used, with a relaxed uncorrelated lognormal molecular clock. Each of the partitions used a HKY substitution model with a gamma distribution of rate variation with 4 categories and estimated base frequencies. Additionally, the mitochondrial and nuclear data sets were partitioned into codon positions $1+2$ and 3 , with unlinked substitution rates and base frequencies across codon positions. The tree-shape prior was set to a birth-death process. The BEAST analysis was run twice to ensure convergence for 1,000 million MCMC generations sampled every 10,000 steps. On completion, the MCMC process was examined using the program Tracer (version 1.7.1) (Rambaut et al., 2014) to ensure convergence and adequate sampling, and the constructed tree was then visualized using FigTree (v1.4.4) (Rambaut, 2006).

\section{7 | Statistical analysis}

We used phylogenetic mixed models to look at the effects of host relatedness on mortality and viral load across the three diet treatments. We fitted all models using a Bayesian approach in the R package MCMCgImm version 2.29 (Hadfield, 2010) in RStudio ( $R$ version 3.5.1) (R Development Core Team, 2005). We used a multivariate model with mortality of the controls, mortality of the virus infected flies and viral load at each of the diets as the response variables. Mortality was calculated as the mean portion of flies alive each day for each vial. The model took the following form:

$$
y_{\text {hit }}=\beta_{1: t}+\text { wingsize } \beta_{2: t}+u_{p: h t}+e_{\text {hit }}
$$

where $y$ is the change in viral load of the ith biological replicate of host species $h$, for trait t. $\beta$ are the fixed effects, with $\beta_{1}$ being the intercepts for each trait and $\beta_{2}$ being the effect of wing size. $U_{p}$ are the random phylogenetic species effects and $e$ the model residuals. The models were also run with a species-specific component independent of phylogeny $\left(u_{s: h t}\right)$ that allow us to estimate the proportion of variation that is not explained by the host phylogeny $\left(v_{s}\right)$ (Longdon et al., 2011). The main model was run without this term as it struggled to separate the phylogenetic and nonphylogenetic terms. Our main model therefore assumes a Brownian motion model of evolution (Felsenstein, 1973). The random effects and the residuals are assumed to be multivariate normal with a zero mean and a covariance structure $V_{p} \otimes A$ for the phylogenetic affects and $V_{\mathrm{e}} \otimes \mathbf{I}$ for the residuals $(\otimes$ here is the Kronecker product). $\mathbf{A}$ is the phylogenetic relatedness matrix, $\mathbf{I}$ is an identity matrix, and the $\mathbf{V}$ are $9 \times 9$ (co)variance matrices describing the (co) variances between viral load, mortality in virus infected, and mortality in controls each at the 3 different diet levels. The phylogenetic covariance matrix, $\mathbf{V}_{\mathbf{p}}$-describes the inter-specific variances in each trait and the inter-specific covariances between them. The residual covariance matrix, $\mathbf{V}_{\mathrm{e}}$, describes the within-species variance that includes both any actual within-species effects and also any measurement or experimental error. The off-diagonal elements in $\mathbf{V}_{\mathbf{e}}$ (the covariances) are unable to be estimated because no vial has multiple measurements-so were set to zero. The MCMC chain was run for 1,300 million iterations with a burn-in of 30 million iterations and a thinning interval of 1 million. Results were tested for sensitivity to the use of different priors by being run with different prior structures (see supplementary $\mathrm{R}$ code), which gave qualitatively similar results. We also ran models with the data subset into viral load and mortality that gave similar results. All confidence intervals (Cl's) reported are $95 \%$ highest posterior density intervals. In order to test for the interaction between diet and species, we calculated correlations between traits from the variance covariance matrix from the diet:species random effect $\left(u_{p: h t}\right)$. If the correlations between traits are close to one and there is no change in the means or the variance, it would suggest that there is no species-by-diet interaction. We confirmed our experimental design and sample sizes had sufficient power to detect effects by down sampling a similar dataset (Roberts et al., 2018).

\section{3 | RESULTS}

In order to investigate the effect that host diet may have on the likelihood of virus host shifts, we quantified DCV viral load in 27 species of Drosophilidae that had been housed on three different diets (Figure 2). Viral loads differed between species, with a billion times more virus in the most susceptible compared to the least susceptible species, consistent with previous studies (Longdon et al., 2015; Roberts et al., 2018). Viral loads were highly repeatable, with the inter-specific phylogenetic component $\left(v_{p}\right)$, explaining a high proportion of the variation in viral load across diets, with little within species or measurement error $\left(v_{\mathrm{e}}\right)$ (Repeatability $=v_{\mathrm{p}} /\left(v_{\mathrm{p}}+v_{\mathrm{e}}\right)$; Low $=0.92$ (95\% Cl: 0.86, 0.96); Medium = 0.90 (95\% Cl: 0.84,0.96); High $=0.83$ (95\% Cl: 0.75, 0.92).

We also partitioned the inter-specific variance into that which can be explained by a Brownian motion model of evolution on the host phylogeny $\left(v_{p}\right)$, and a species-specific component independent of the phylogeny $\left(v_{s}\right)$. The proportion of the between species variance that can be explained by the phylogeny can then be calculated, using $v_{p} /\left(v_{p}+v_{s}\right)$ (Freckleton et al., 2002), and can be equated to the phylogenetic heritability or Pagel's lambda (Housworth et al., 2004; Pagel, 1999). We found that the host phylogeny explained a modest amount of the inter-specific variation in viral loads across diets; however, these estimates had broad confidence intervals ( Low $=0.20$ (95\% Cl: $\left.3.5 \times 10^{-6}, 0.63\right)$; Medium = $0.34\left(95 \% \mathrm{Cl}: 2.0 \times 10^{-6}, 0.80\right.$ ); High $=0.51\left(95 \% \mathrm{Cl}: 3.2 \times 10^{-6}, 0.88\right)$, due to the model struggling to separate out the phylogenetic and nonphylogenetic components.

In order to examine whether the susceptibility of species responded in the same or different ways to the changes in diet, we examined viral load across the different protein: carbohydrate ratios. We found strong positive inter-specific correlations between viral loads across diet treatments suggesting the species are responding in similar ways to the changes in dietary ratios (Table 1). There was a decline in the between species variance in the high diet 
FIGURE 2 (a) Phylogeny of the 27 Drosophilidae host species. Scale bar is the number of substitutions per site. (b) Change in RNA viral load $\left(\log _{2}\right)$ for the host species infected with DCV across the three different diets of differing protein: carbohydrate ratios. Individual points are plotted with a small $x$-axis jitter and represent the change in viral load between day 0 and day 2-post-infection. Panels are ordered as on the tips of the phylogeny in (a) (a)

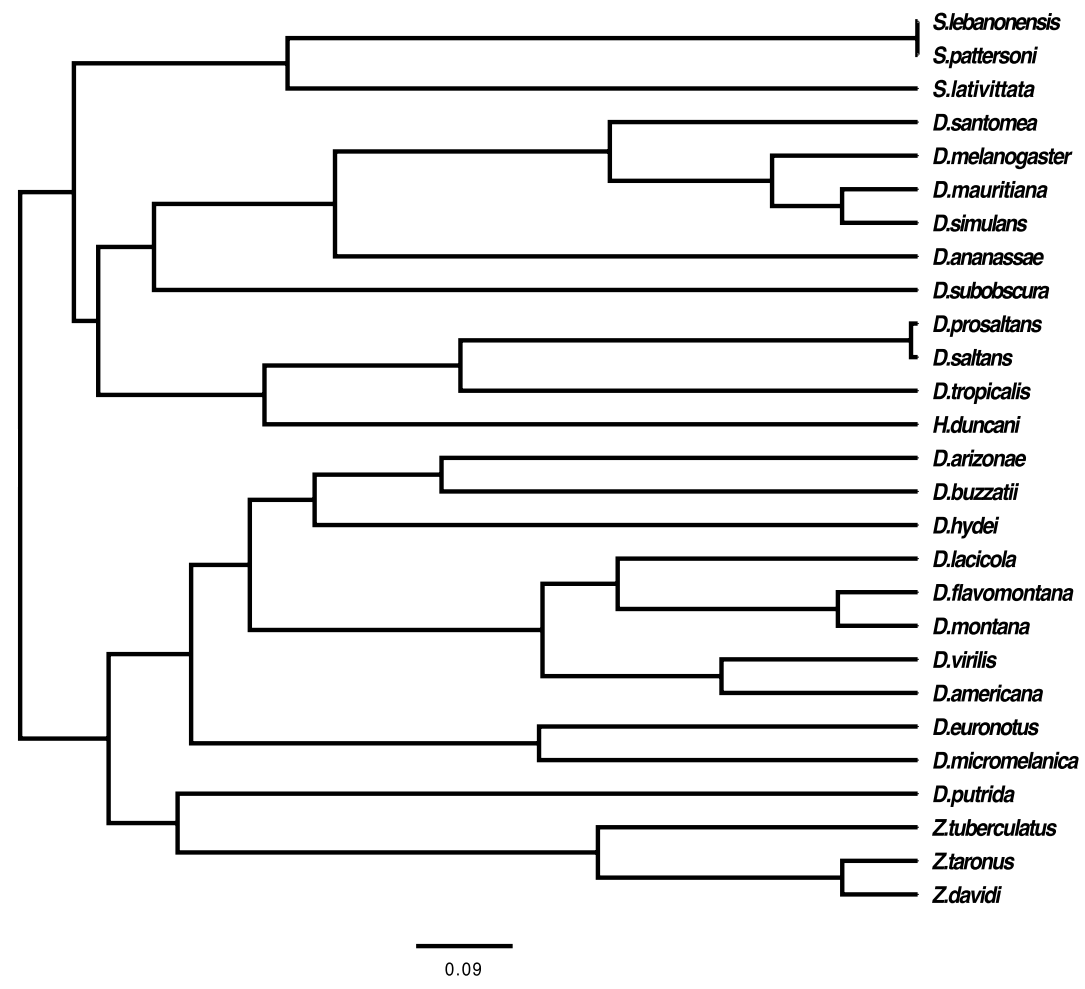

(b)

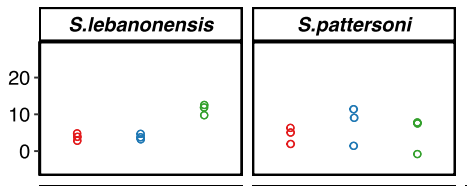

Protein: Carbohydrate
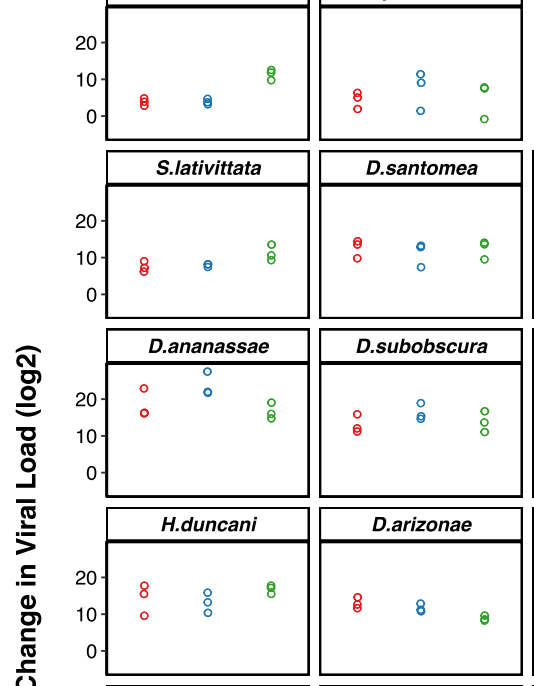

D.ananassae
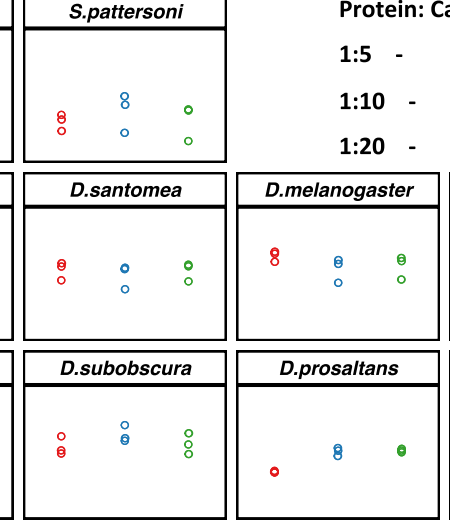

High
Medium
Low

\begin{tabular}{|c|c|c|}
\hline \multicolumn{3}{|c|}{ D.mauritiana } \\
\hline 。 & 8 & 8 \\
\hline & & 。 \\
\hline
\end{tabular}

0

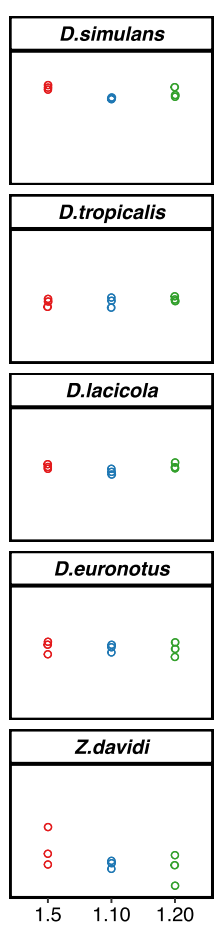

Food (Ratio Protein:Carbohydrate)

compared to low and medium-but this was not significantly different $\left(v_{p}\right.$ : Low $=77.13$ (95\% Cl: 35.09, 125.50); Medium = $82.33(95 \%$ $\mathrm{Cl}: 37.55,135.26)$; High $=45.59(95 \% \mathrm{Cl}: 19.61,76.39)$ and mean viral loads were similar across the diets (Low $=11.4$ (95\% Cl: 5.3 ,
17.7); Medium = 10.6 (95\% Cl: 3.6, 16.6); High = 10.6 (95\% Cl: 3.6, 16.7). Residual variance did not differ significantly between treatments (Low $=6.45$ (95\% Cl: 4.87, 8.04); Medium = $8.23(95 \% \mathrm{Cl}$ : $6.45,10.35)$; High = 8.32 (95\% Cl: 6.54, 10.6). 
As similar pathogen loads can cause different levels of harm to their hosts (Boots, 2008; Råberg et al., 2009; Roy \& Kirchner, 2000), we examined if virus induced mortality differed across diets over a 20-day period after viral challenge (Figure 3). We found differences in the virulence (mortality) caused by DCV between host species, with some species seeing no apparent change in mortality over the experimental period compared to sham infected controls (e.g. S. pattersoni and D. saltans), whilst other species show higher susceptibility with up to $50 \%$ of flies dead by day 10 post-infection (e.g. D. simulans and D. melanogaster). As with the viral load data, we calculated the repeatability of survival in these virus infected flies which was high in all cases (Repeatability; Low $=0.90(95 \% \mathrm{Cl}$ : 0.78, 0.98); Medium = 0.87 (95\% Cl: 0.71,0.97); High $=0.98(95 \% \mathrm{Cl}$ : $0.85,1.00)$. We also calculated the proportion of between species variance that can be explained by the phylogeny for the virus infected flies (Phylogenetic effect: Low $=0.16$ (95\% Cl: $2.58 \times 10^{-6}$, $0.62)$; Medium $=0.18\left(95 \% \mathrm{Cl}: 5.75 \times 10^{-7}, 0.78\right)$; High $=0.32(95 \%$ $\left.\mathrm{Cl}: 7.75 \times 10^{-8}, 0.87\right)$, which-like the viral load data-had broad confidence intervals due to the model struggling to separate the phylogenetic and nonphylogenetic components.

We found strong positive inter-specific correlations between the survival of virus challenged flies across the diets, suggesting the species are responding in similar ways to the dietary changes (Table 1). Among species variance in mortality of virus infected flies was consistent across diets (Low $=0.18(95 \% \mathrm{Cl}$ : 0.07, 0.31); Medium $=0.16$ (95\% Cl: 0.04, 0.30); High $=0.12$ (95\% Cl: 0.04, 0.23) as was the mean mortality (Low $=0.64$ (95\% Cl: $0.47,0.82)$; Medium $=0.58(95 \% \mathrm{Cl}$ : $0.38,0.75)$; High $=0.65(95 \% \mathrm{Cl}: 0.47,0.82)$. The residual variance

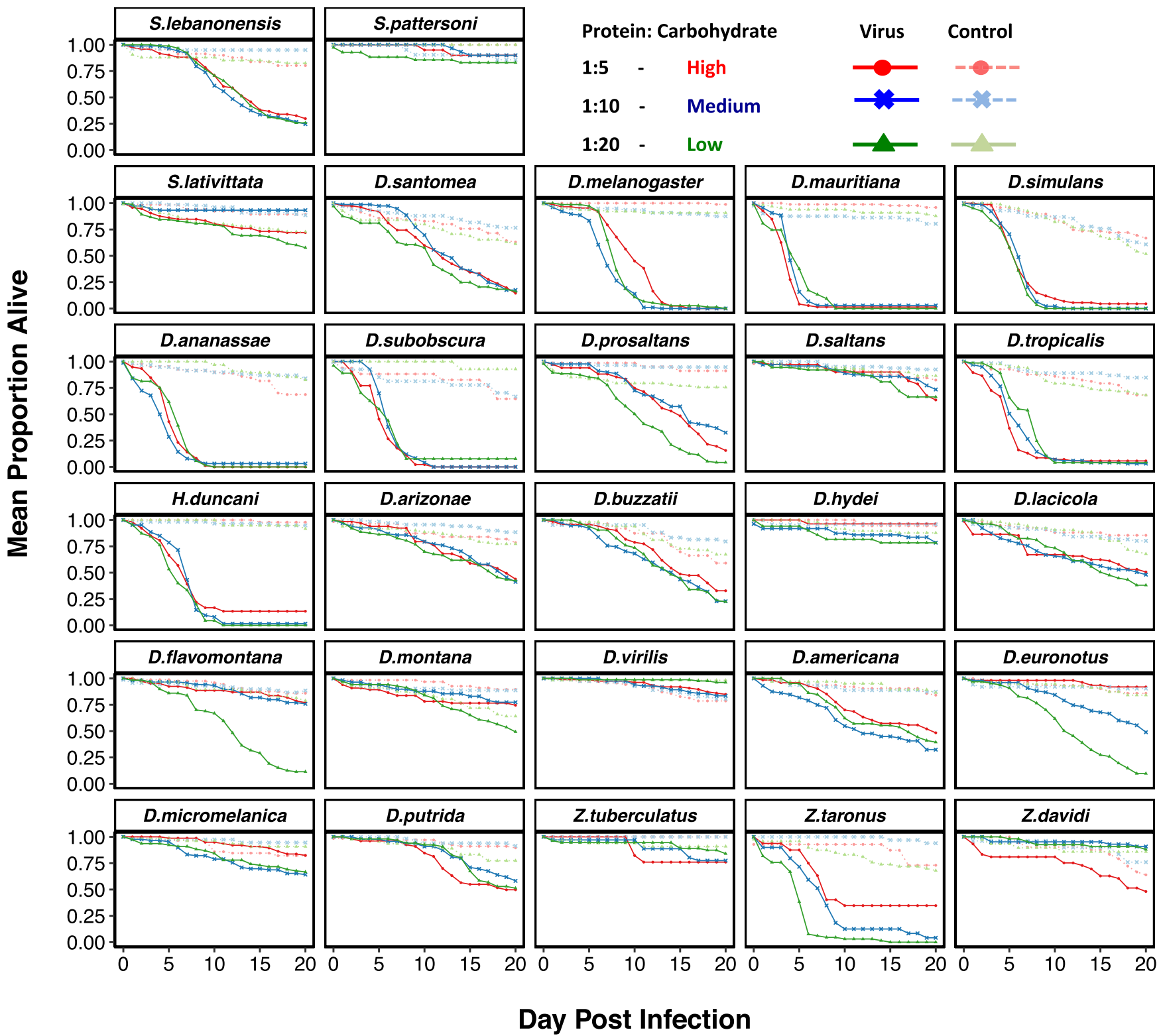

FIGURE 3 Mortality in 27 species of Drosophilidae housed on three different diets of varying protein: carbohydrate ratios. High-red circles, Medium-blue crosses and Low-green triangles and either control sham infected (dashed line) or virally challenged with DCV (solid lines). Panels are labelled in line with the tips in Figure $2 a$ 
was also consistent across the diets ( $\operatorname{Low}=0.02$ (95\% Cl: $0.01,0.03$ ); Medium $=0.02$ (95\% Cl: 0.01, 0.04); High $=0.02$ (95\% Cl: 0.01, 0.03).

We found that there were strong positive correlations between mortality and RNA viral load (inter-specific correlations between viral load and survival of virus infected flies: Low $=0.89(95 \% \mathrm{Cl}$ : $0.78,0.98)$; Medium = 0.85 (95\% Cl: 0.67, 0.97); High = $0.67(95 \% \mathrm{Cl}$ : $0.35,0.90)$. To confirm that these differences are due to mortality caused by the virus rather than intrinsic differences in the survivorship of the different species, we also inoculated flies with a control solution. There was far less mortality in the controls than the virus infected flies (Figure 3). There was inter-specific variation in control mortality (Low $=0.18(95 \% \mathrm{Cl}: 0.01,0.59)$; Medium $=0.43(95 \% \mathrm{Cl}$ : $0.01,0.76)$; High $=0.55(95 \% \mathrm{Cl}:-0.72,1.00)$, but this was not significantly correlated with survival of the virus infected flies (survival of control vs. virus infected on: Low $=-0.11(95 \% \mathrm{Cl}$ : $-0.92,0.75)$; Medium $=0.34$ (95\% Cl: -0.48 0.97); High $=0.12$ (95\% Cl: -0.82 , 0.89). We found no effect of wing length as a proxy for body size, (mean: $-0.05,95 \% \mathrm{Cl}:-0.13,0.05$ ).

\section{4 | DISCUSSION}

We found dietary treatments of differing protein to carbohydrate ratios did not alter the outcome of infection in 27 species of Drosophilidae infected with DCV. We found strong positive interspecific correlations across diets in both viral load and mortality (Table 1), suggesting that the species are in general responding in similar ways to nutritional changes. Despite there being among species variation in susceptibility, changes in diet in general did not affect viral loads, nor did they alter the likelihood of surviving an infection. We found strong positive correlations between mortality and viral load on each of the diets, suggesting the amount of harm caused to a host is a result of virus accumulation caused by infection.

Although the point estimates of the inter-specific correlations are close to one (Table 1)-suggesting overall there is limited evidence for interactions between species and diet, some species do appear to show differences in mortality on different diets (e.g. D. euronotus and D. flavomontana, Figure 3). These patterns, however, are not present when looking at the viral load data for these species, and our power analysis suggests we should have enough power to detect interaction effects with our present experimental design. Therefore, further experiments designed to look specifically at the differences within species are required to determine whether these patterns of mortality would hold true.

Both mounting and maintaining an immune response requires energy and nutrients. During an acute immune challenge, the provisioning of nutrients may become more demanding for a host, with pathogen induced malabsorption through damage to, or obstruction of, digestive tissues (Lochmiller \& Deerenberg, 2000). DCV is known to cause severe pathology of the tissues of the digestive tract with subsequent accumulation of food in the crop (food storage organ) and obstruction in the intestine (Chtarbanova et al., 2014). These physical symptoms alter an infected hosts energy stores with infected flies showing significantly reduced glycogen and triglyceride levels three to four days post-infection (Chtarbanova et al., 2014). DCV-infected flies also have increased body mass, with a reduced food intake and reduced metabolism, suggesting that they experience increased water retention (Arnold et al., 2013; Chtarbanova et al., 2014; Thomas-Orillard, 1984). We therefore hypothesized that changing the ratio of protein to carbohydrate in the diet may alter outcome of infection, and as species may all have their own 'optimal diet', that species may respond in different ways to such dietary changes. However, this does not appear to be the case.

Geometric frameworks for nutrition were developed in response to the fact that what is 'optimal' will depend on a balance of particular nutrients in the organism and trait being investigated (Archer et al., 2009; Cotter et al., 2019; Simpson \& Raubenheimer, 1995). For example, mice infected with Salmonella were found to survive better on diets containing a higher ratio of protein to carbohydrate (Peck et al., 1992). As were army worm caterpillars infected with bacteria, with survival increasing with dietary protein, suggesting high protein requirements are associated with bacterial resistance (Povey et al., 2009). A recent study used 10 different protein: carbohydrate diets and challenged flies with Pseudomonas entomophila bacteria (Savola, Montgomery, et al., 2020). Survival on low protein diets was found to be lower in infected flies, and suggested protein was important for survival during infection. This study also monitored lifespan and reproduction in flies, and found that regardless of injury and infection, dietary restriction extended lifespan and reduced reproductive output (Savola, Montgomery, et al., 2020). One potential mechanism of the interaction of diet and infection has been suggested in research using a model host-pathogen system in vivo and in vitro (Wilson et al., 2020). Caterpillars of S. littoralis challenged with the bacteria $X$. nematophila-in vivo and on high dietary protein had slower bacterial growth with higher survival. When this was combined with in vitro experiments, the results suggested this was driven by the osmolality of the hosts' blood (haemolymph) being altered by an increase in solutes in the high protein diets slowing the bacterial growth (Wilson et al., 2020).

Further research on the mechanistic basis of dietary effects on resistance is needed for other pathogen taxa, including viruses. Immunity to DCV inoculation in D. melanogaster has been reported to involve the JAK/STAT and Imd pathways, and potentially phagocytosis (Lamiable et al., 2016; Van Rij et al., 2006; Zhu et al., 2013). Additionally, the RNAi pathway is a key antiviral defence mechanism in Drosophila and DCV appears to have evolved to suppress this response (Van Rij et al., 2006). Although we find no interaction between dietary protein: carbohydrate and susceptibility, the multifaceted immune response to DCV may be energetically costly, and other nutrients may interact with the ability of a host to allocate resources between an immune response, damage repair and the maintenance of homeostasis (Lochmiller \& Deerenberg, 2000; Sadd \& Siva-Jothy, 2006; Schmid-Hempel, 2005; Zuk \& Stoehr, 2002). For example, lipid and fats have been associated with $D$. melanogaster response to DCV viral infection; peroxisomes were found to be required for host defence to infection, through their primary function in lipid metabolism (Chtarbanova et al., 2014). The lipid level across 
our diets was held constant, but this could be a potential area for further study. There has been an increased use of a chemically defined (holidic) diet in order to manipulate individual nutrients present in fly diets (Lee et al., 2006). Exome matched diets have been shown to alleviate trade-offs in fecundity and longevity (Piper et al., 2017). A possible extension of this would be to look at the effect of matching diets to transcriptional changes during infection, and seeing if this alleviates (or exacerbates) pathology.

Changes in diet have been shown to alter pathogen susceptibility in a number of systems. We hypothesized that changes in diet could alter the potential outcomes of virus host shifts. However, we found that overall changes in the ratio of protein to carbohydrate did not alter susceptibility to DCV across host species in this instance. This suggests dietary protein to carbohydrate ratios is not universally important in determining susceptibility to pathogens. It is unclear if the lack of studies showing no effect of diet reflects publication biases or whether our model system is unusual. However, it highlights the need to examine the importance of diet in explaining susceptibility to pathogens across a broad range of host and pathogen taxa.

\section{ACKNOWLEDGMENTS}

KER and BL are supported by a Sir Henry Dale Fellowship jointly funded by the Wellcome Trust and the Royal Society (grant no. 109356/Z15/Z). We would like to thank Darren Obbard, Jarrod Hadfield, Ruth Archer, E. Savola and Sophie Evision for their useful discussion as well as three anonymous reviewers for constructive comments. For the purpose of Open Access, the author has applied a CC BY public copyright licence to any Author Accepted Manuscript version arising from this submission.

\section{CONFLICT OF INTEREST}

Authors declare no conflict of interest.

\section{AUTHOR CONTRIBUTIONS}

KER conceived, designed and carried out the experiment, and both KER and $\mathrm{BL}$ analysed, wrote and edited the manuscript and agreed to the final submitted version.

\section{PEER REVIEW}

The peer review history for this article is available at https://publo ns.com/publon/10.1111/jeb.13773.

\section{OPEN RESEARCH BADGES}

\section{(1)}

This article has been awarded Open Data and Open Materials Badges. All materials and data are publicly accessible via the Open Science Framework at mcmcglmm_data_diet.csv Dataset: https:// doi.org/10.6084/m9.figshare.13079465.v1, R_script_diet.R. figshare: https://doi.org/10.6084/m9.figshare.13079351.v1, Genbank accession numbers of sequences used to infer the host phylogeny.xIsx. figshare. Dataset: https://doi.org/10.6084/m9.figshare.13079366.v1 and Tree. figshare: https://doi.org/10.6084/m9.figshare.13079402.v1.

\section{DATA AVAILABILITY STATEMENT}

mcmcglmm_data_diet.csv. figshare. Dataset. https://doi.org/10.6084/ m9.figshare.13079465.v1.

R_script_diet.R. figshare. Online resource. https://doi.org/10.6084/ m9.figshare.13079351.v1.

GenBank accession numbers of sequences used to infer the host phylogeny.xlsx. figshare. Dataset. https://doi.org/10.6084/m9.figsh are.13079366.v1.

Tree. figshare. Dataset. https://doi.org/10.6084/m9.figshare.13079 402.v1.

\section{ORCID}

Katherine E. Roberts iD https://orcid.org/0000-0002-8567-3743

Ben Longdon (iD https://orcid.org/0000-0001-6936-1697

\section{REFERENCES}

Anderson, R. M., Latorre-Esteves, M., Neves, A. R., Lavu, S., Medvedik, O., Taylor, C. et al. (2003). Yeast life-span extension by calorie restriction is independent of NAD fluctuation. Science (80-), 302, 2124-2126.

Archer, C. R., Royle, N., South, S., Selman, C., \& Hunt, J. (2009). Nutritional geometry provides food for thought. Journals of Gerontology Series A Biological Sciences and Medical Sciences, 64, 956-959.

Arnold, P. A., Johnson, K. N., \& White, C. R. (2013). Physiological and metabolic consequences of viral infection in Drosophila melanogaster. Journal of Experimental Biology, 216, 3350-3357.

Ayres, J. S., \& Schneider, D. S. (2009). The role of anorexia in resistance and tolerance to infections in Drosophila. PLoS Biology, 7, e1000150.

Bedhomme, S., Agnew, P., Sidobre, C., \& Michalakis, Y. (2004). Virulence reaction norms across a food gradient. Proceedings of the Royal Society B-Biological Sciences, 271, 739-744.

Blanford, S., \& Thomas, M. B. (1999). Host thermal biology: the key to understanding host-pathogen interactions and microbial pest control? Agricultural and Forest Entomology, 1, 195-202.

Blum, J. E., Fischer, C. N., Miles, J., \& Handelsman, J. (2013). Frequent replenishment sustains the beneficial microbiome of Drosophila melanogaster. MBio, 4, 1-8.

Boots, M. (2008). Fight or learn to live with the consequences? Trends in Ecology and Evolution, 23, 248-250.

Broderick, N. A., \& Lemaitre, B. (2012). Gut-associated microbes of Drosophila melanogaster. Gut Microbes, 3, 307-321.

Brooks, D. R., \& Hoberg, E. P. (2007). How will global climate change affect parasite-host assemblages? Trends in Parasitology, 23, 571-574.

Bunning, H., Bassett, L., Clowser, C., Rapkin, J., Jensen, K., House, C. M. et al. (2016). Dietary choice for a balanced nutrient intake increases the mean and reduces the variance in the reproductive performance of male and female cockroaches. Ecology and Evolution, 6, 4711-4730.

Camus, M. F. F., Fowler, K., Piper, M. W. D., \& Reuter, M. (2017). Sex and genotype effects on nutrient-dependent fitness landscapes in Drosophila melanogaster. Proceedings of the Royal Society B: Biological Sciences, 284, 20172237.

Carlson, C. J., Albery, G. F., Merow, C., Trisos, C. H., Zipfel, C. M., Eskew, E. A. et al. (2020). Climate change will drive novel cross-species viral transmission. bioRxiv 2020.01.24.918755.

Cherry, S., \& Perrimon, N. (2004). Entry is a rate-limiting step for viral infection in a Drosophila melanogaster model of pathogenesis. Nature Immunology, 5, 81-87. 
Christian, P. D. (1987). Studies on Drosophila C and A viruses in Australian populations of Drosophila melanogaster. Australian National University.

Chtarbanova, S., Lamiable, O., Lee, K.-Z., Galiana, D., Troxler, L., Meignin, C. et al. (2014). Drosophila C virus systemic infection leads to intestinal obstruction. Journal of Virology, 88, 14057-14069.

Cotter, S. C., Reavey, C. E., Tummala, Y., Randall, J. L., Holdbrook, R., Ponton, F. et al. (2019). Diet modulates the relationship between immune gene expression and functional immune responses. Insect Biochemistry and Molecular Biology, 109, 128-141.

Cotter, S. C., Simpson, S. J., Raubenheimer, D., \& Wilson, K. (2011). Macronutrient balance mediates trade-offs between immune function and life history traits. Functional Ecology, 25, 186-198.

Cumnock, K., Gupta, A. S., Lissner, M., Chevee, V., Davis, N. M., \& Schneider, D. S. (2018). Host energy source is important for disease tolerance to malaria. Current Biology, 28, 1635-1642.e3.

Drummond, A., Suchard, M., Xie, D., \& Rambaut, A. (2012). Bayesian phylogenetics with BEAUti and the BEAST 1.7. Molecular Biology and Evolution, 29, 1969-1973.

Fanson, B. G., Weldon, C. W., Pérez-Staples, D., Simpson, S. J., \& Taylor, P. W. (2009). Nutrients, not caloric restriction, extend lifespan in Queensland fruit flies (Bactrocera tryoni). Aging Cell, 8, 514-523.

Fellous, S., \& Lazzaro, B. P. (2010). Larval food quality affects adult (but not larval) immune gene expression independent of effects on general condition. Molecular Ecology, 19, 1462-1468.

Felsenstein, J. (1973). Maximum-likelihood estimation of evolutionary trees from continuous characters. American Journal of Human Genetics, 25, 471-492.

Ferreira, Á. G., Naylor, H., Esteves, S. S., Pais, I. S., Martins, N. E., \& Teixeira, L. (2014). The toll-dorsal pathway is required for resistance to viral oral infection in drosophila. PLoS Pathogens, 10(12), e1004507. http://dx.doi.org/10.1371/journal.ppat.1004507

Freckleton, R. P., Harvey, P. H., \& Pagel, M. (2002). Phylogenetic analysis and comparative data: $\mathrm{A}$ test and review of evidence. The American Naturalist, 160, 712-726.

Grueber, C. E., Gray, L. J., Morris, K. M., Simpson, S. J., \& Senior, A. M. (2018). Intergenerational effects of nutrition on immunity: a systematic review and meta-analysis. Biological Reviews of the Cambridge Philosophical Society, 93, 1108-1124.

Hadfield, J. D. (2010). MCMC methods for multi-response generalized linear mixed models: The MCMCgImm R package. Journal of Statistical Software, 33, 1-22.

Hall, S. R., Knight, C. J., Becker, C. R., Duffy, M. A., Tessier, A. J., \& Cáceres, C. E. (2009). Quality matters: Resource quality for hosts and the timing of epidemics. Ecology Letters, 12, 118-128.

Harvell, C. D., Mitchell, C. E., Ward, J. R., Altizer, S., Dobson, A. P., Ostfeld, R. S. et al. (2002). Climate warming and disease risks for terrestrial and marine biota. Science, 296, 2158-2162.

Hayman, D. T. S., Pulliam, J. R. C., Marshall, J. C., Cryan, P. M., \& Webb, C. T. (2016). Environment, host, and fungal traits predict continentalscale white-nose syndrome in bats. Science Advances, 2, e1500831.

Henry, Y., \& Colinet, H. (2018). Microbiota disruption leads to reduced cold tolerance in Drosophila flies. Science Nature, 105, 59.

Henry, Y., Overgaard, J., \& Colinet, H. (2020). Dietary nutrient balance shapes phenotypic traits of Drosophila melanogaster in interaction with gut microbiota. Comparative Biochemistry and Physiology Part A: Molecular \& Integrative Physiology, 241, 110626.

Hoberg, E. P., \& Brooks, D. R. (2015). Evolution in action: climate change, biodiversity dynamics and emerging infectious disease. Philosophical Transactions of the Royal Society B: Biological Sciences 370: 20130553

Housworth, E. A., Martins, E. P., \& Lynch, M. (2004). The phylogenetic mixed model. The American Naturalist, 163, 84-96.

Howick, V. M.\& Lazzaro, B.P. (2014). Genotype and diet shape resistance and tolerance across distinct phases of bacterial infection. BMC Evolutionary Biology, 14(1), 56. http://dx.doi.org/10.1186/1471-2148-14-56
Huey, R. B., Moreteau, B., Moreteau, J.-C., Gibert, P., Gilchrist, G. W., Ives, A. R. et al. (2006). Sexual size dimorphism in a Drosophila clade, the D. obscura group. Zoology, 109, 318-330.

Jensen, K., McClure, C., Priest, N. K., \& Hunt, J. (2015). Sex-specific effects of protein and carbohydrate intake on reproduction but not lifespan in Drosophila melanogaster. Aging Cell, 14, 605-615.

Jousset, F. X., Plus, N., Croizier, G., \& Thomas, M. (1972). [Existence in Drosophila of 2 groups of picornavirus with different biological and serological properties]. Comptes Rendus Hebdomadaires Des Séances De L'académie Des Sciences. Série D, 275, 3043-3046.

Kearse, M., Moir, R., Wilson, A., Stones-Havas, S., Cheung, M., Sturrock, S. et al. (2012). Geneious Basic: An integrated and extendable desktop software platform for the organization and analysis of sequence data. Bioinformatics, 28, 1647-1649.

Keaton Wilson, J., Ruiz, L., \& Davidowitz, G. (2019). Dietary protein and carbohydrates affect immune function and performance in a specialist herbivore insect (Manduca sexta). Physiological and Biochemical Zoology, 92, 58-70.

Kirk, D., Jones, N., Peacock, S., Phillips, J., Molnár, P. K., Krkošek, M. et al. (2018). Empirical evidence that metabolic theory describes the temperature dependency of within-host parasite dynamics. PLoS Biology, 16, e2004608.

Klass, M. R. (1983). A method for the isolation of longevity mutants in the nematode Caenorhabditis elegans and initial results. Mechanisms of Ageing and Development, 22, 279-286.

Knutie, S. A., Wilkinson, C. L., Wu, Q. C., Ortega, C. N., \& Rohr, J. R. (2017). Host resistance and tolerance of parasitic gut worms depend on resource availability. Oecologia, 183, 1031-1040.

Kraaijeveld, A. R., \& Godfray, H. C. (1997). Trade-off between parasitoid resistance and larval competitive ability in Drosophila melanogaster. Nature, 389, 278-280.

Kutzer, M. A. M., \& Armitage, S. A. O. (2016). The effect of diet and time after bacterial infection on fecundity, resistance, and tolerance in Drosophila melanogaster. Ecology and Evolution, 6, 4229-4242.

Lamiable, O., Arnold, J., de Faria, I. J. S., Olmo, R. P., Bergami, F., Meignin, C., et al. (2016). Analysis of the contribution of hemocytes and autophagy to Drosophila Antiviral immunity. Journal of Virology, 90, 5415-5426.

Lazzaro, B. P., \& Little, T. J. (2009). Immunity in a variable world. Philosophical Transactions of the Royal Society of London. Series B, Biological Sciences, 364, 15-26.

Le Couteur, D. G., Solon-Biet, S., Cogger, V. C., Mitchell, S. J., Senior, A., De Cabo, R. et al. (2016). The impact of low-protein high-carbohydrate diets on aging and lifespan. Cellular and Molecular Life Sciences, 73, 1237-1252.

Lee, K., Cory, J., Wilson, K., Raubenheimer, D., \& Simpson, S. (2006). Flexible diet choice offsets protein costs of pathogen resistance in a caterpillar. Proceedings of the Royal Society B: Biological Sciences, 273, 823-829.

Lee, K. P., Simpson, S. J., \& Wilson, K. (2008). Dietary protein-quality influences melanization and immune function in an insect. Functional Ecology, 22, 1052-1061.

Lesperance, D. N. A., \& Broderick, N. A. (2020). Meta-analysis of diets used in Drosophila microbiome research and introduction of the Drosophila dietary composition calculator (DDCC). G3 Genes, Genomes, Genetics, 10, 2207-2211.

Lochmiller, R. L., \& Deerenberg, C. (2000). Trade-offs in evolutionary immunology: Just what is the cost of immunity? Oikos, 88, 87-98.

Longdon, B., Cao, C., Martinez, J., \& Jiggins, F. M. (2013). Previous exposure to an RNA virus does not protect against subsequent infection in Drosophila melanogaster. PLoS One, 8, e73833.

Longdon, B., Day, J. P., Alves, J. M., Smith, S. C. L., Houslay, T. M., McGonigle, J. E. et al. (2018). Host shifts result in parallel genetic changes when viruses evolve in closely related species. PLOS Pathogens, 14, e1006951. 
Longdon, B., Hadfield, J. D., Day, J. P., Smith, S. C. L., McGonigle, J. E., Cogni, R. et al. (2015). The causes and consequences of changes in virulence following pathogen host shifts. PLOS Pathogens, 11, e1004728.

Longdon, B., Hadfield, J. D., Webster, C. L., Obbard, D. J., \& Jiggins, F. M. (2011). Host phylogeny determines viral persistence and replication in novel hosts. PLOS Pathogens, 7, e1002260.

Maklakov, A. A., Hall, M. D., Simpson, S. J., Dessmann, J., Clissold, F. J., Zajitschek, F. et al. (2009) Sex differences in nutrient-dependent reproductive ageing. Aging Cell, 8, 324-330.

McKean, K. A., Yourth, C. P., Lazzaro, B. P., \& Clark, A. G. (2008). The evolutionary costs of immunological maintenance and deployment. BMC Evolutionary Biology, 8, 76.

Merkling, S. H., \& van Rij, R. P. (2015). Analysis of resistance and tolerance to virus infection in Drosophila. Nature Protocols, 10, 1084-1097.

Moatt, J. P., Savola, E., Regan, J. C., Nussey, D. H., \& Walling, C. A. (2020). Lifespan extension via dietary restriction: time to reconsider the evolutionary mechanisms? BioEssays, 42, 1900241.

Nakagawa, S., Lagisz, M., Hector, K. L., \& Spencer, H. G. (2012). Comparative and meta-analytic insights into life extension via dietary restriction. Aging Cell, 11, 401-409.

Pagel, M. (1999). Inferring the historical patterns of biological evolution. Nature, 401, 877-884.

Peck, M. D., Babcock, G. F., \& Alexander, J. W. (1992). The role of protein and calorie restriction in outcome from Salmonella infection in mice. Journal of Parenteral and Enteral Nutrition, 16, 561-565.

Pike, V. L., Lythgoe, K. A., \& King, K. C. (2019). On the diverse and opposing effects of nutrition on pathogen virulence. Proceedings of the Royal Society B-Biological Sciences, 286, 20191220.

Piper, M. D. (2017). Using artificial diets to understand the nutritional physiology of Drosophila melanogaster. Current Opinion in Insect Science, 23, 104-111.

Piper, M. D. W., Soultoukis, G. A., Blanc, E., Mesaros, A., Herbert, S. L., Juricic, P. et al. (2017). Matching dietary amino acid balance to the in silico-translated exome optimizes growth and reproduction without cost to lifespan. Cell Metabolism, 25, 610-621.

Ponton, F., Wilson, K., Cotter, S. C., Raubenheimer, D., \& Simpson, S. J. (2011). Nutritional immunology: A multi-dimensional approach. PLOS Pathogens, 7, e1002223.

Ponton, F., Wilson, K., Holmes, A. J., Cotter, S. C., Raubenheimer, D., \& Simpson, S. J. (2013). Integrating nutrition and immunology: a new frontier. Journal of Insect Physiology, 59, 130-137.

Povey, S., Cotter, S. C., Simpson, S. J., Lee, K. P., \& Wilson, K. (2009). Can the protein costs of bacterial resistance be offset by altered feeding behaviour? Journal of Animal Ecology, 78, 437-446.

Povey, S., Cotter, S. C., Simpson, S. J., \& Wilson, K. (2014). Dynamics of macronutrient self-medication and illness-induced anorexia in virally infected insects. Journal of Animal Ecology, 83, 245-255.

$R$ Development Core Team (2005). $R$ : A language and environment for statistical computing. R Foundation for Statistical Computing.

Råberg, L., Graham, A. L., \& Read, A. F. (2009). Decomposing health: Tolerance and resistance to parasites in animals. Philosophical Transactions of the Royal Society B: Biological Sciences, 364, 37-49.

Rambaut, A. (2006). FigTree v1.4.4. Retrieved from http://tree.bio.ed.ac. uk/software/figtree/

Rambaut, A., Suchard, M., Xie, D., \& Drummond, A. (2014). Tracer v1.6.

Rao, S., Schieber, A. M. P., O'Connor, C. P., Leblanc, M., Michel, D., \& Ayres, J. S. (2017). Pathogen-mediated inhibition of anorexia promotes host survival and transmission. Cell, 168, 503-516.e12.

Raubenheimer, D. \& Simpson, S. J. (1999). Integrating nutrition: A geometrical approach. Entomologia Experimentalis et Applicata, 91(1), 6782. http://dx.doi.org/10.1046/j.1570-7458.1999.00467.x

Roberts, K. E., Hadfield, J. D., Sharma, M. D., \& Longdon, B. (2018). Changes in temperature alter the potential outcomes of virus host shifts. PLOS Pathogens, 14, e1007185.

Roy, B. A., \& Kirchner, J. W. (2000). Evolutionary dynamics of pathogen resistance and tolerance. Evolution (N.Y), 54, 51-63.
Sadd, B. M., \& Siva-Jothy, M. T. (2006). Self-harm caused by an insect's innate immunity. Proceedings. Biological Sciences, 273, 2571-2574.

Savola, E., Montgomery, C., Waldron, F. M., Monteith, K., Vale, P., \& Walling, C. A. (2020). Testing evolutionary explanations for the lifespan benefit of dietary restriction in Drosophila melanogaster. bioRxiv. https://doi.org/10.1101/2020.06.18.159731

Savola, E., Vale, P., \& Walling, C. (2020). Larval diet affects adult reproduction but not survival regardless of injury and infection stress in Drosophila melanogaster. bioRxiv. https://doi. org/10.1101/2020.10.16.342618

Schmid-Hempel, P. (2005). Evolutionary ecology of insect immune defenses. Annual Review of Entomology, 50, 529-551.

Sheldon, B. C., \& Verhulst, S. (1996). Ecological immunology: Costly parasite defences and trade offs in evolutionary ecology. Trends in Ecology \& Evolution, 11, 317-321.

Simpson S.J., Raubenheimer D. (1995). The geometric analysis of feeding and nutrition: a user's guide. Journal of Insect Physiology, 41, (7), $545-$ 553. http://dx.doi.org/10.1016/0022-1910(95)00006-g.

Simpson, S. J., \& Raubenheimer, D. (2011). The nature of nutrition: A unifying framework. Australian Journal of Zoology, 59, 350-368.

Siva-Jothy, M. T., \& Thompson, J. J. W. (2002). Short-term nutrient deprivation affects immune function. Physiological Entomology, 27, 206-212.

Skorupa, D. A., Dervisefendic, A., Zwiener, J., \& Pletcher, S. D. (2008). Dietary composition specifies consumption, obesity, and lifespan in Drosophila melanogaster. Aging Cell, 7, 478-490.

Sullivan, W., Ashburner, M., \& Hawley, R. S. (2000). Drosophila protocols. Cold Spring Harbor Laboratory Press.

Thomas-Orillard, M. (1984). Modifications of mean ovariole number, fresh weight of adult females and developmental time in Drosophila melanogaster induced by Drosophila C virus. Genetics, 107, 635-63544.

Vale, P. F., \& Jardine, M. D. (2017). Infection avoidance behavior: Viral exposure reduces the motivation to forage in female Drosophila melanogaster. Fly (Austin), 11, 3-9.

Van Rij, R. P., Saleh, M. C., Berry, B., Foo, C., Houk, A., Antoniewski, C. et al. (2006). The RNA silencing endonuclease Argonaute 2 mediates specific antiviral immunity in Drosophila melanogaster. Genes \& Development, 20, 2985-2995.

Weindruch, R., \& Walford, R. L. (1982). Dietary restriction in mice beginning at 1 year of age: Effect on life-span and spontaneous cancer incidence. Science (80-. ), 215, 1415-1418.

Wilson, K., Holdbrook, R., Reavey, C. E., Randall, J. L., Tummala, Y., Ponton, F. et al. (2020). Osmolality as a novel mechanism explaining diet effects on the outcome of infection with a blood parasite. Current Biology, 30, 2459-2467.

Woolhouse, M. E. J., Haydon, D. T., \& Antia, R. (2005). Emerging pathogens: the epidemiology and evolution of species jumps. Trends in Ecology \& Evolution, 20, 238-244.

Zhu, F., Ding, H., \& Zhu, B. (2013). Transcriptional profiling of Drosophila S2 cells in early response to Drosophila C virus. Virology Journal, 10, 210.

Zuk, M., \& Stoehr, A. M. (2002). Immune defense and host life history. The American Naturalist, 160, S9-S22.

\section{SUPPORTING INFORMATION}

Additional supporting information may be found online in the Supporting Information section.

How to cite this article: Roberts KE, Longdon B. Viral susceptibility across host species is largely independent of dietary protein to carbohydrate ratios. J Evol Biol. 2021;34:746-

756. https://doi.org/10.1111/jeb.13773 